\title{
Electronic Health Records Functionalities in Saudi Arabia: Obstacles and Major Challenges
}

\author{
A. Karim Jabali ${ }^{1}$ \& Mu’taman Jarrar $^{2}$ \\ ${ }^{1}$ College of Applied Medical Sciences, Imam Abdulrahman Bin Faisal University, Dammam, Saudi Arabia \\ ${ }^{2}$ College of Medicine, Imam Abdulrahman Bin Faisal University, Dammam, Saudi Arabia \\ Correspondence: A. Karim Jabali, Associate Professor, PhD, Health Informatics, Imam Abdulrahman Bin Faisal \\ University, P.O. Box 1982, Dammam 31441, Saudi Arabia. Tel: 966-133-332-491. E-mail: aajabali@iau.edu.sa
}

\author{
Received: January 23, 2018 Accepted: February 26, 2018 Online Published: March 5, 2018 \\ doi:10.5539/gjhs.v10n4p50 URL: https://doi.org/10.5539/gjhs.v10n4p50
}

\begin{abstract}
Background and Objectives: Despite the innovative technology availability, however, the functionalities of usefulness are limited and not been explored in Saudi Arabian hospitals. This study aims to determine the extent and diffusion of Electronic Health Records (EHR) in public hospitals in Saudi Arabia and to explore the main obstacles, and problems of adopting EHR in these hospitals.
\end{abstract}

Methods: A comprehensive survey was developed and sent to the medium and large size hospital stakeholders to collect their opinions on the current status of the adoption and usage of EHR. Cluster random sampling has been used. The study has been conducted in the eastern province.

Results: Based on the 15 hospitals surveyed in the Eastern Province (EP), Saudi Arabia, a total of seven hospitals $(46.6 \%)$ had an EHR system and the implementation is running. EHR is mostly used for order entry $(51.11 \%)$ and char review (41.11\%) in the EP in Saudi Arabia with obstacles to be used for decision support, documentation functions, communication tools. Despite the "secured" EHR system, the results shows that security mechanism did not cover all threats.

Conclusion: The results suggest that more public hospitals are required to adopting more and more EHR and EHR functionalities. A periodic assessment of EHR status should be performed in addition to or part of an encouraging/ enforcing policies that can significantly increase the rate of adoption of EHR systems. Managers and policymakers can benefit from the study by facing obstacles and general challenges of problems like resistance to change from the medical staff in using the information technology, low and weak financing, and train technical supporting staff for adopting EHR.

Keywords: electronic health records, adopting EHR, information technology, Saudi Arabia

\section{Introduction}

With a goal to achieve paperless or complete EHR, the adoption of EHR started in most countries around the world. Meanwhile, the work on adoption of EHR passes through stages and phases, and this resulted in differences in the adoption level from one country to another, and between private and public sectors, and among hospitals. The last fact is influenced by many technical, managerial, and financial factors and leads to a need for studies to evaluate and document the experience obtained along the journey toward full functioning EHR (Ferris, Shields, Ph, Rosenbaum, \& Blumenthal, 2009). Moreover, such studies reveal different lessons that can be used to accelerate and enhance the pace of getting benefits from these systems (Catherine, Affairs, \& Vol, 2015; Ferris et al., 2009; Middleton, Hammond, Brennan, \& Cooper, 2005). Periodic progress reports on what is going on the EHR adoption scene in Saudi Arabia government sector, and how the process of adoption moves toward its goals is the concern of this work.

From the available research work, it is clearly seen that despite the good understanding of the benefits of electronic health records among different healthcare providers (Birkhead, Klompas, \& Shah, 2015), and a noticeable increase in the adoption of EHR by different health-care workers, the process of adoption of electronic health records, in general, still slower than expected or projected especially in rural and small hospitals (Catherine et al., 2015) and will have to accelerate above its current pace to achieve the goals of complete paperless EHR within the planned time frame (Adler-milstein et al., 2015; Jha et al., 2018). 
Starting from early years of the current century, many research works were carried out to evaluate the level and extent of EHR adoption in the US, where the emphasis is on what had been achieved and how to accelerate the adoption process (Middleton et al., 2005). Nowadays, and looking back to what was suggested and what was done during the last 15 years, it is clear that most of the recommendations of earlier works found their way to real life of many hospitals in US.

According to the Center for Medicare and Medicaid Services CMS, there has seen unprecedented growth in the adoption and meaningful use of EHR in USA. Between 2009 and 2012, EHR adoption nearly doubled among physicians and more than tripled among hospitals (Tagalicod \& Reider, 2013). This is a result of the decision to direct additional funding and incentives to "adopters" of EHR and follow the concept of "meaningful use" by the year 2014 (Tagalicod \& Reider, 2013). Based on the Canada Health Infoway Annual Report 2014-2015, this success is also seen in Canada, the National Physician Survey revealed that 77 percent of family physicians were using EHRs, triple the number from 2007 to 2014. Locally in Saudi Arabia, Ministry of Health (MOH) starting from the early days of new century recognized the importance of transforming the health sector into electronic based automated healthcare provision system. In 2011, MOH launched the National E-health Strategy according to which there are two phases: each one extends for five years to get the goals reached (National E-health Strategy, 2011).

Many research works were done and continue to appear about different aspects of EHR. Most work of researchers was focused on benefits of using the new system in this or that context (Ben-assuli, 2018), but a new line of research work nowadays went deeper into exploiting the benefits in diagnosing and analyzing different medical causes and phenomena using the tools and data provided by EHR systems. For example, there are many articles that discuss the issue of quality control and monitoring using EHR (Frederick, 2018; Rowland et al., 2018), while other articles investigate the use of for example the built in features like alerts to improve documentation and counseling (Bae, Huerta, \& Ford, 2016), or alerts to predict mortality among patients (Khurana et al., 2016).

Other authors even come to conclusion about using of EHR for interventional studies and prospective trials at the point of care and the impact of EHR on population health and other related problems (Sutherland, Kaelber, Downing, Goel, \& Longhurst, 2016; Webber, 2016). Hence, it is expected that the potential of EHR will be more and more explored and it will not be very far when the connection of EHR data to intelligent decision support systems will be part of most if not all treatment stages.

The difficulties of adoption are common in literature. Many research articles focus on these problems and they suggest some solutions (Alharthi et al., 2011; Jabali, 2017; Love, 2016). In this regard, Adler-milstein, et.al 2015, explored obstacles related to financial allocations, physician cooperation, and complexity of achieving goals in the projected time frame in USA. Few studies explored these challenges in Saudi Arabia, and not yet been explored in the EP. This study aims to explore the diffusion, obstacles, and problems of adopting EHR in the EP hospitals in Saudi Arabia.

\section{Methods}

\subsection{Design}

This a cross-sectional survey conducted in Saudi Arabia. Cluster random Sampling used to classify the country by regions and the hospitals by hospital size. The study was carried out in the EP of Saudi Arabia and covered only medium and large public hospitals of the region. Based on the current medical research medium size hospitals refer to those hospitals have 110-199 beds (Jarrar, Abdul Rahman, \& Shamsudin, 2015). The large hospitals are defined in this study as those with at least 200 beds. The study was carried out using a web-based questionnaire. The targeted category of people was the heads of information technology departments in these hospitals. The survey time started in May 2014 and ended in July 2014. The project is part of a periodic progress assessment of different aspects of EHR in the region, and it is planned to carry out similar studies periodically to track the developments in the field.

\subsection{Data Collection}

The final version of the survey used in the study was adopted after deep review of previous studies performed in the region and in different countries. This review resulted in consideration of new aspects related to public sector hospitals. Moreover, new questions were added to address those aspects like multi-branching i.e. hospitals with more one branch in the region, ownership and the questions related to assessment of EHR by the Health care Information Management systems society (HIMSS).The web survey software, SurveyMonkey $\mathbb{C}$, was used to develop the questionnaire.

The questionnaire starts with general questions about the person who completes the survey to identify his role in 
the hospital's hierarchy. Then a set of questions about the hospital are asked like the type, size, and location of the hospital and the year of its establishment. Another set of Questions are asked on the different functionalities in the EHR system; chart review, decision support, order entry, documentation and communication. Several questions are asked on the security of the EHR system. A general question is asked on the other additional tools present in the EHR system. An open-ended question was asked on the problems that the IT heads faced in implementation of EHR in their hospitals.

According to Saudi MOH Statistical Book 2013, the number of public hospitals in the EP is 18 with 3,056 beds or 10.4 beds per 10,000 populations. These hospitals are different in many aspects, like number of beds, number of outpatient clinics available, some of them are classified as general and others as specialist hospitals. In this study, only those hospitals with 100 beds and over were targeted. Here, it was revealed that 15 of these hospitals (83\%) are medium and large hospitals. Electronically, the survey was sent to the information Technology (IT) heads of these hospitals, and all of them were responded and completed the survey.

Validation checks were included in the data capture template to reduce data capture errors. For hospitals without an internet connection, the questionnaire was sent by e-mail or fax. The obtained data was reviewed and analyzed with the help of Microsoft Excel and the results are presented here.

\section{Results}

A total of fifteen medium and large public hospitals participated in the study. There were five (33.3\%) specialist hospitals while the $9(60 \%)$ hospitals were general hospitals and only one $(7 \%)$ is a university hospital. Regarding the location of the hospitals, three (20\%) are in one city Al-Khobar, other three in Dhahran, while $6(40 \%)$ are in Dammam and the remaining three hospitals are located in Ibqiq, Ihsa, and Qatif. Regarding the size of the hospitals, it is revealed that 9 of them are with number of beds between 100 and 300 beds, while 6 are with more than 300 beds.

The IT heads are of different background and qualifications. Three of them are of computer science and engineering professional background, two with medical and allied medical sciences, while two are from health information management field. From the other side, most of the responded hospitals $12(80 \%)$ had more than 10 full time staff in the EHR Department and this could be an indication of the level of services delivered by these departments. Answering the question about the type of EHR of these hospitals, three responded that their systems are in-house developed, two are from-on-the-shelf, and two did not specified.

The answer to the main question about the level and extent of the adoption of EHR in public hospitals is shown in Table 1. Here it is revealed that from the responding hospitals, only seven hospitals (46.6\%) had a complete HER system and the implementation is running. Four hospitals (26.6\%) are progressing in the implementation of EHR systems, three of the hospitals $(20 \%)$ completed the implementation but their systems are not yet running, and one hospital doesn't yet started the implementation of EHR.

Table 1. The stage of implementation of EHR

\begin{tabular}{lll}
\hline Stage of implementation & No of Hospitals (Total N=15) & $\%$ \\
\hline Completed and the system is running & 7 & $46.6 \%$ \\
Implementation in progress & 4 & $26.6 \%$ \\
Implementation completed but the system is not yet running & 3 & $20 \%$ \\
Not yet started & 1 & $6.7 \%$ \\
\hline
\end{tabular}

In order to explore the main obstacles, and problems of adopting EHR in these hospitals, leaders answered open ended questions regarding the usefulness of EHR in the hospital activates; namely: chart review, decision support, order entry, documentation functions, communication tools, and other additional activities. EHR is mostly used for order entry and char review in the EP in Saudi Arabia. As shown in Table 2, 51.11\% of leaders among the 15 hospitals participated in the study used the EHR for order entry (lab, radiology and pharmacy orders). Further, 41.11\% leaders used it as well for chart review (lab and radiology results is the most commonly used). However, only $28.3 \%, 28.33,17.78$ and 23.33 have been used the EHR for decision support, documentation functions, communication tools and other additional activities; respectively. The overall functionalities of the EHR is low, only $31.54 \%$ of managers in the participated hospitals are agreed the usefulness of the key function of electronic recording system. 
Table 2. The usefulness of EHR in the hospital activates

\begin{tabular}{|c|c|c|c|c|c|}
\hline Category & Dimension & $\begin{array}{l}\text { Accomplished } \\
\text { and Used }\end{array}$ & $\begin{array}{l}\text { Not } \\
\text { Used }\end{array}$ & $\begin{array}{l}\text { Not } \\
\text { Available }\end{array}$ & IC \\
\hline \multirow[t]{6}{*}{ Chart review } & Obtain \& review lab results & 8 & 0 & 0 & 7 \\
\hline & Obtain \& review radiology results & 8 & 0 & 0 & 7 \\
\hline & Obtain \& review other test results & 8 & 0 & 0 & 7 \\
\hline & Create \& review scanned documents & 4 & 2 & 3 & 6 \\
\hline & Review progress notes & 3 & 2 & 3 & 7 \\
\hline & Monitor current \& past medications \& their refill & 6 & 1 & 1 & 7 \\
\hline $\operatorname{Avg}(\%)$ & & 41.11 & 5.56 & 7.78 & 45.56 \\
\hline \multirow[t]{4}{*}{ Decision support } & $\begin{array}{l}\text { Receive drug interaction alerts when writing } \\
\text { prescriptions }\end{array}$ & 5 & 1 & 2 & 7 \\
\hline & $\begin{array}{l}\text { Receive drug-allergy alerts when writing } \\
\text { prescriptions }\end{array}$ & 5 & 2 & 1 & 7 \\
\hline & $\begin{array}{l}\text { Highlighting of test results that are out of normal } \\
\text { range }\end{array}$ & 7 & 0 & 2 & 6 \\
\hline & Clinical guidelines & 0 & 1 & 4 & 10 \\
\hline Avg (\%) & & 28.33 & 6.67 & 15.00 & 50.00 \\
\hline \multirow[t]{3}{*}{ Order entry } & Enter lab orders & 8 & 0 & 0 & 7 \\
\hline & Enter radiology orders & 8 & 0 & 0 & 7 \\
\hline & Enter pharmacy orders & 7 & 0 & 1 & 7 \\
\hline Avg (\%) & & 51.11 & 0.00 & 2.22 & 46.67 \\
\hline \multirow[t]{4}{*}{$\begin{array}{l}\text { Documentation } \\
\text { functions }\end{array}$} & $\begin{array}{l}\text { Create and maintain patient-related medical } \\
\text { problem list }\end{array}$ & 3 & 2 & 4 & 6 \\
\hline & Create and maintain common medication list & 4 & 2 & 3 & 6 \\
\hline & Identify patient-specific allergies & 6 & 2 & 1 & 6 \\
\hline & Document patient-discharge instructions & 4 & 2 & 3 & 6 \\
\hline $\operatorname{Avg}(\%)$ & & 28.33 & 13.33 & 18.33 & 40.00 \\
\hline \multirow{3}{*}{$\begin{array}{l}\text { Communication } \\
\text { tools }\end{array}$} & Email system & 3 & 4 & 2 & 6 \\
\hline & Facsimile (FAX) system & 1 & 1 & 6 & 7 \\
\hline & Cell phone Short Message Service (SMS) system & 4 & 2 & 3 & 6 \\
\hline Avg $(\%)$ & & 17.78 & 15.56 & 24.44 & 42.22 \\
\hline \multirow[t]{6}{*}{ Additional } & Managing patient referrals & 5 & 2 & 1 & 7 \\
\hline & $\begin{array}{l}\text { Allowing physicians, when out of the hospital, to } \\
\text { use internet to access patient health records }\end{array}$ & 2 & 2 & 4 & 7 \\
\hline & $\begin{array}{l}\text { Allowing patients to use internet to access parts of } \\
\text { their health records }\end{array}$ & 1 & 0 & 8 & 6 \\
\hline & $\begin{array}{l}\text { Automatic coding of disease conditions (e.g. ICD } \\
\text { codes) }\end{array}$ & 2 & 2 & 5 & 6 \\
\hline & Generating health statistics & 5 & 1 & 3 & 6 \\
\hline & Data backup and disaster recovery & 6 & 0 & 2 & 7 \\
\hline $\operatorname{Avg}(\%)$ & & 23.33 & 7.78 & 25.56 & 43.33 \\
\hline Overall Avg (\%) & & 31.54 & 7.95 & 15.90 & 44.62 \\
\hline
\end{tabular}


The number of functionalities in operation is better than in governance and support (not adequately regarded for decision support of communications). This is seen in the fact that more than half of the hospitals are using the main ancillary subsystems of EHR to enter, obtain and review radiology, pharmacy, and laboratory orders and results. More advanced functionalities like, reviewing progress notes, receiving drug-allergy alerts and drug- drug interaction while writing prescription are less used. Giving physicians and patients outside accessibility to EHR besides using SMS, email, and Facsimile notifications is rarely used. This may be due to problems and difficulties related to the availability of internet services, and the fact that still most people prefer to use direct voice call for communications about their health issues.

As shown in Figure 1, a surprising finding is that the majority of the hospitals IT managers, two thirds, consider their EHR system "secured" despite the fact that a number of respondents admits that their security mechanism did not cover all threats. There is no agreement among respondents about the use of such mechanism like "backup and disaster recovery' which can be considered as one of the basic functionalities to secure any IT system. Moreover, the situation about commonly affecting malicious malware like phishing, flooding, snatched websites, spam filtration, and denial of access attacks is not good. The awareness regarding so called "Public Key Infrastructure" security instrumental tool is absolutely problematic, none of the IT heads of the hospitals positively responded on the availability of such mechanism. This may show that there is not a clear understanding of some kinds of threats and the mechanisms required to deal with them. Hence, the results indicate clearly on the necessity to develop training programs for staff in these areas.

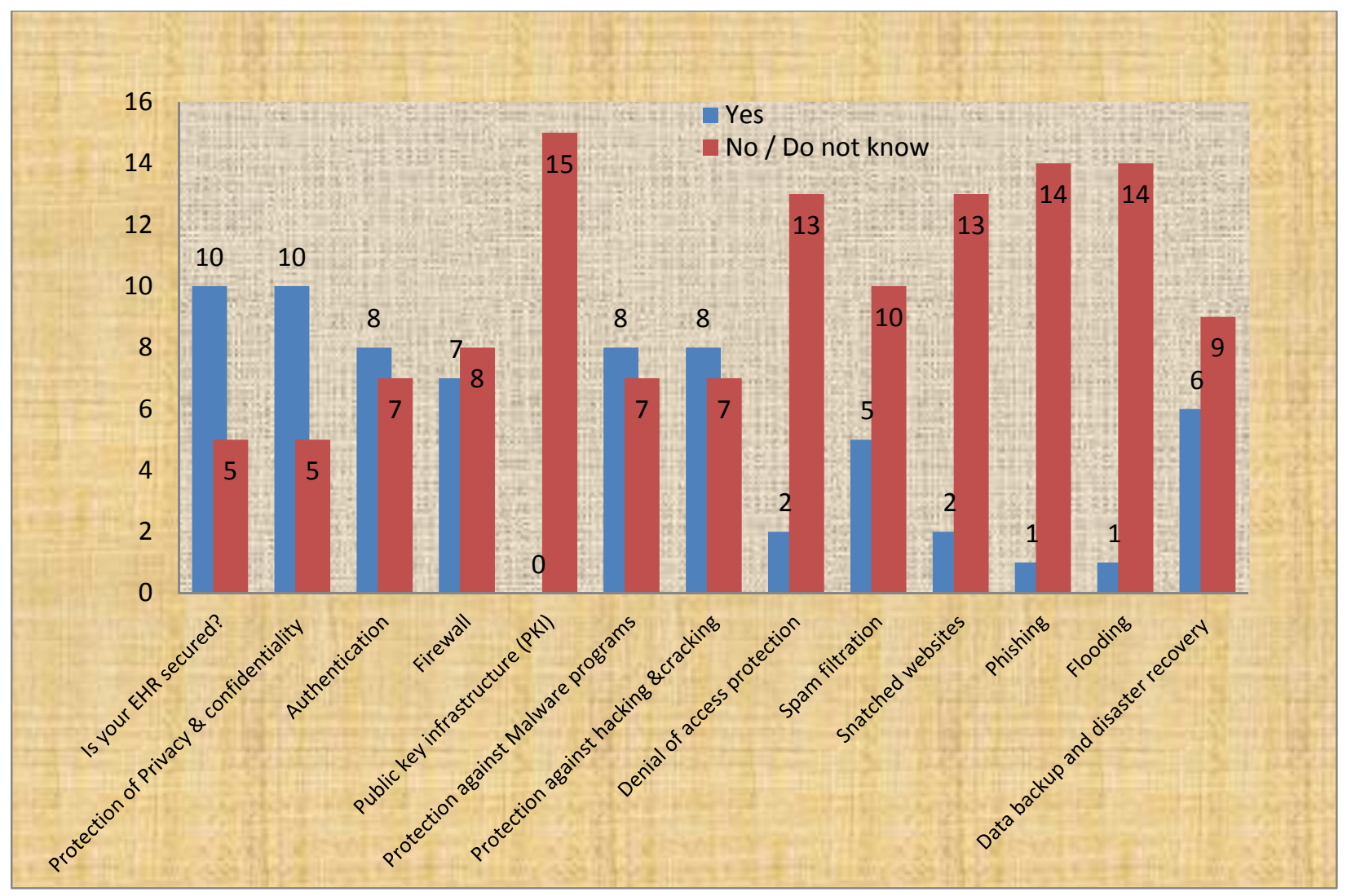

Figure 1. Data safety

\section{Discussion}

The adoption of EHR is becoming faster and more subsystems and functionalities are emerging into real life. It is required for optimizing the clinical outcomes, quality and safety (Boonstra, Versluis, \& Vos, 2014; M. Jarrar, Abdul Rahman, \& Don, 2015). However, the results show that hospitals are required adopting more and more EHR and EHR functionalities. A periodic assessment of EHR status should be performed in addition to or part of an encouraging/ enforcing policies that can significantly increase the rate of adoption of EHR systems. The study results are consistent with previous studies (Catherine et al., 2015; Ferris et al., 2009; Rowland et al., 2018), 
several obstacles limiting the functionalities of using the EHR in the decision support, documentation functions, communication tools and other additional activities which is necessary for optimizing the outcomes of health services provided. It is required to conduct training for healthcare providers to optimize the functionalities of EHR is the EP hospitals. Managers and policymakers can benefit from the study by facing obstacles and general challenges of problems like resistance to change from the medical staff in using the information technology, low and weak financing, and train technical supporting staff for adopting HER. The awareness among the hospitals' IT heads, regarding the benefits of using the electronic records was very limited in the EP. This was consistent with the previous studies (Ben-assuli, 2018; Ferris et al., 2009). Allocation of resources required to fund training workshops for the frontline worker as well as leaders in the hospitals in EP. Several studies agreed the benefits of using the information technology and HER in hospitals (Gray et al., 2014; Nguyen, Bellucci, \& Nguyen, 2014; Yazici, 2014). This can secure the confidentiality of patient records as well as provide a historical progress of the patient that can be used for continuity of patient care or for conducting longitudinal researches.

The study is cross-sectional and limited to EP in Saudi Arabia. Further study required with larger sample size by including hospital leaders from the hospitals in the other rejoins in the kingdom to specify the exact obstacles. Further, the study was limited to the medium and large size hospitals (hospitals with more than 100 beds). Future research required to explore whither large hospitals are more likely to have established HER than small hospitals. The study surveyed one teaching hospital, which is not compared with other 14 non-teaching hospitals (the response bias will be misleading). Interesting future research required to explore the hospital teaching status and its association with the adoption and functionalities of EHR.

\section{Conclusion}

This study explored the functionalities and obstacles of adopting EHR in the EP hospitals. One of two medium and large size hospitals in the EP is using the EHR. However, there are advanced functionalities like, reviewing progress notes, receiving drug-allergy alerts and drug- drug interaction while writing prescription were rarely used. Managers and policy makers can require allocating resources to train staff and encourage them using the hospital facilities and information technology in order to enhance the outcomes of patient care and maintain the confidentiality of patient records.

\section{Competing Interests Statement}

The authors declare that there are no competing or potential conflicts of interest.

\section{References}

Adler-milstein, J., Desroches, C. M., Kralovec, P., Foster, G., Worzala, C., Charles, D., ... Jha, A. K. (2015). Electronic Health Record Adoption In US Hospitals: Progress Continues, But Challenges Persist Julia. Health Affairs, 34(12), 2174-2180.

Alharthi, H., Ali, A., Mahalli, E., Jabali, A., Al-qahtani, M., \& Al-kahtani, N. (2011). Annual Survey on the Level and Extent of Usage of Electronic Health Records in Government-related Hospitals in Eastern Province , Saudi Arabia. Perspectives in Health Information Management / AHIMA, American Health Information Management Association, 8(Fall).

Bae, J., Huerta, T. R., \& Ford, E. W. (2016). Cardiovascular disease documentation and counseling in electronic medical records. Preventive Medicine, 88(2016), 27-32. https://doi.org/10.1016/j.ypmed.2016.03.017

Ben-assuli, O. (2018). Electronic health records, adoption, quality of care, legal and privacy issues and their implementation in emergency departments. Health Policy, 119(3), 287-297. https://doi.org/10.1016/j.healthpol.2014.11.014

Birkhead, G. S., Klompas, M., \& Shah, N. R. (2015). Uses of Electronic Health Records for Public Health Surveillance to Advance Public Health. The Annual Review of Public Healt, (36), 345-59. https://doi.org/10.1146/annurev-publhealth-031914-122747

Boonstra, A., Versluis, A., \& Vos, J. F. J. (2014). Implementing electronic health records in hospitals: A systematic literature review. BMC Health Services Research, 14(1), 1-24. https://doi.org/10.1186/1472-6963-14-370

Canada Health Infoway Annual Report 2014-2015, The Path of Progress, available at https://www.infoway-inforoute.ca/en/component/edocman/resources/i-infoway-i-corporate/annual-reports/2 771-annual-report-2014-2015?Itemid=101

Catherine, M., Affairs, A. K. H., \& Vol, C. C. (2015). Electronic Health Record Adoption In US Hospitals: Progress Continues, But Challenges Persist. ProQuest, 34, 1-9. 
Ferris, T. G., Shields, A., Ph, D., Rosenbaum, S., \& Blumenthal, D. (2009). Use of Electronic Health Records in U.S. Hospitals. The New England Journal of Medicine.

Frederick, S. A. (2018). Advanced Technology in Pediatric Intensive Care Units: Have They Improved Outcomes? Pediatric Clinics of NA, 63(2), 293-301. https://doi.org/10.1016/j.pcl.2015.12.003

Gray, S. H., Pasternak, R. H., Gooding, H. C., Woodward, K., Hawkins, K., Sawyer, S., \& Anoshiravani, A. (2014). Recommendations for electronic health record use for delivery of adolescent health care. Journal of Adolescent Health, 54(4), 487-490. https://doi.org/10.1016/j.jadohealth.2014.01.011

Jabali, A. K. (2017). Progress in adopting EHR in Saudi eastern region private hospitals. International Journal of Healthcare Management, 10(1), 13-19.

Jarrar, M., Abdul Rahman, H., \& Don, M. S. (2015). Optimizing Quality of Care and Patient Safety in Malaysia: The Current Global Initiatives, Gaps and Suggested Solutions. Global Journal of Health Science, 8(6). https://doi.org/10.5539/gjhs.v8n6p75

Jarrar, M., Abdul Rahman, H., \& Shamsudin, A. S. (2015). The Impact of Patient to Nurse Ratio on Quality of Care and Patient Safety in the Medical and Surgical Wards in Malaysian Private Hospitals: A Cross-sectional Study. Asian Social Science, 11(9), 326-332. https://doi.org/10.5539/ass.v11n9p326

Jha, A. K., Burke, M. F., Desroches, C., Joshi, M. S., Kralovec, P. D., Campbell, E. G., \& Buntin, M. B. (2018). Progress Toward Meaningful Use: Hospitals 'Adoption of Electronic Health Records. The American Journal of Managed Care, 17(2011), 1-6.

Khurana, H. S., Groves, R. H., Simons, M. P., Martin, M., Stoffer, B., Kou, S., .. Parthasarathy, S. (2016). Real-Time Automated Sampling of Electronic Medical Records Predicts Hospital Mortality. American Journal of Medicine, 129(7), 688-698.e2. https://doi.org/10.1016/j.amjmed.2016.02.037

Love, V. D. (2016). Improving electronic health record adoption among rural health-care workers: A correlational study. Dissertation Abstracts International Section A: Humanities and Social Sciences, 77(3-A(E)), No-Specified. Retrieved from http://ovidsp.ovid.com/ovidweb.cgi?T=JS\&PAGE=reference \&D=psyc $13 \&$ $\mathrm{NEWS}=\mathrm{N} \& \mathrm{AN}=2016-37851-254$

Middleton, B., Hammond, E., Brennan, P. F., \& Cooper, G. F. (2005). Accelerating U. S. EHR Adoption: How to Get There From Here. Journal of the American Medical Informatics Association, 12(1), 13-20. https://doi.org/10.1197/jamia.M1669.The

Ministry of Health statistics book, Saudi Arabia (2013). Retrieved from www.moh.gov.sa/en/Ministry/Statistics/book/ Documents/Statistics-Book-1434.pdf

National e-Health Strategy of Saudi Arabia. (2011), Retrieved from http://www.moh.gov.sa/en/Ministry/nehs/Pages/The-Complete-Vision.aspx

Nguyen, L., Bellucci, E., \& Nguyen, L. T. (2014). Electronic health records implementation: An evaluation of information system impact and contingency factors. International Journal of Medical Informatics, 83(11), 779-796. https://doi.org/10.1016/j.ijmedinf.2014.06.011

Rowland, J. H., Control, C., Sciences, P., Hewitt, M., Survivorship, C., Ganz, P. A., ... Angeles, L. (2018). Cancer Survivorship: A New Challenge in Delivering Quality Cancer Care. Journal of Clinical Oncology, 24(32), 32-35. https://doi.org/10.1200/JCO.2006.09.2700

Sutherland, S. M., Kaelber, D. C., Downing, N. L., Goel, V. V., \& Longhurst, C. A. (2016). Electronic Health Record-Enabled Research in Children Using the Electronic Health Record for Clinical Discovery. Pediatric Clinics of North America, 63(2), 251-268. https://doi.org/10.1016/j.pcl.2015.12.002

Tagalicod, R., \& Reider, J. (2013). Progress on adoption of electronic health records, "Progress on Adoption of Electronic Health Records". Centers for Medicare and Medicaid Services. Retrieved from https://www.cms.gov/eHealth/ListServ_Stage3Implementation.html

Webber, E. C. (2016). Population Health and Pediatric Informatics. Pediatric Clinics of North America, 63(2), 221-237. https://doi.org/10.1016/j.pcl.2015.12.001

Yazici, H. J. (2014). An exploratory analysis of hospital perspectives on real time information requirements and perceived benefits of RFID technology for future adoption. International Journal of Information Management, 34(5), 603-621. https://doi.org/10.1016/j.ijinfomgt.2014.04.010 


\section{Copyrights}

Copyright for this article is retained by the author(s), with first publication rights granted to the journal.

This is an open-access article distributed under the terms and conditions of the Creative Commons Attribution license (http://creativecommons.org/licenses/by/4.0/). 